\title{
BMJ Open Medical Marijuana and Opioids (MEMO) Study: protocol of a longitudinal cohort study to examine if medical cannabis reduces opioid use among adults with chronic pain
}

\author{
Chinazo O Cunningham (D) , ${ }^{1}$ Joanna L Starrels, ${ }^{1}$ Chenshu Zhang, ${ }^{1}$ \\ Marcus A Bachhuber, ${ }^{2}$ Nancy L Sohler, ${ }^{3}$ Frances R Levin, ${ }^{4}$ Haruka Minami, ${ }^{5}$ \\ Deepika E Slawek, ${ }^{1}$ Julia H Arnsten ${ }^{1}$
}

To cite: Cunningham $\mathrm{CO}$, Starrels JL, Zhang C, et al. Medical Marijuana and Opioids (MEM0) Study: protocol of a longitudinal cohort study to examine if medical cannabis reduces opioid use among adults with chronic pain. BMJ Open 2020;10:e043400. doi:10.1136/ bmjopen-2020-043400

- Prepublication history for this paper is available online To view these files, please visit the journal online (http://dx.doi. org/10.1136/bmjopen-2020043400).

Received 03 August 2020 Revised 29 November 2020 Accepted 30 November 2020

D) Check for updates

(C) Author(s) (or their employer(s)) 2020. Re-use permitted under CC BY-NC. No commercial re-use. See rights and permissions. Published by BMJ.

For numbered affiliations see end of article.

\section{Correspondence to} Dr Chinazo 0 Cunningham; chinazo.cunningham@ einsteinmed.org

\section{ABSTRACT}

Introduction In the USA, opioid analgesic use and overdoses have increased dramatically. One rapidly expanding strategy to manage chronic pain in the context of this epidemic is medical cannabis. Cannabis has analgesic effects, but it also has potential adverse effects. Further, its impact on opioid analgesic use is not well studied. Managing pain in people living with HIV is particularly challenging, given the high prevalence of opioid analgesic and cannabis use. This study's overarching goal is to understand how medical cannabis use affects opioid analgesic use, with attention to $\Delta 9$ tetrahydrocannabinol and cannabidiol content, HIV outcomes and adverse events.

Methods and analyses We are conducting a cohort study of 250 adults with and without HIV infection with (a) severe or chronic pain, (b) current opioid use and (c) who are newly certified for medical cannabis in New York. Over 18 months, we collect data via in-person visits every 3 months and web-based questionnaires every 2 weeks. Data sources include: questionnaires; medical, pharmacy and Prescription Monitoring Program records; urine and blood samples; and physical function tests. Using marginal structural models and comparisons within participants' 2-week time periods (unit of analysis), we will examine how medical cannabis use (primary exposure) affects (1) opioid analgesic use (primary outcome), (2) HIV outcomes (HIV viral load, CD4 count, antiretroviral adherence, HIV risk behaviours) and (3) adverse events (cannabis use disorder, illicit drug use, diversion, overdose/deaths, accidents/ injuries, acute care utilisation).

Ethics and dissemination This study is approved by the Montefiore Medical Center/Albert Einstein College of Medicine institutional review board. Findings will be disseminated through conferences, peer-reviewed publications and meetings with medical cannabis stakeholders.

Trial registration number ClinicalTrials.gov Registry (NCT03268551); Pre-results.

\section{INTRODUCTION}

Chronic pain is common among American adults and particularly among people living
Strengths and limitations of this study

- This study examines how long-term medical cannabis use affects opioid analgesic use, including products with different $\Delta 9$-tetrahydrocannabinol and cannabidiol content.

- The study also examines how long-term medical cannabis use affects HIV outcomes and adverse events.

- Measurement of cannabis and opioid use will be precise given 39 self-reported measures every 2 weeks, along with dispensing data from New York's Prescription Monitoring Program.

- Because medical cannabis products dispensed to participants have undergone independent laboratory evaluation, the exact content of these products is known and accurate.

- Because the study design is a longitudinal cohort study, analyses examine changes over time within participants, and biases that could affect outcomes may be unmeasured.

with HIV. ${ }^{1-17}$ To address pain, over the past decades, opioid analgesic use has dramatically increased. ${ }^{18} \quad 19$ Subsequently, opioid use disorder and overdose have increased to unprecedented levels. ${ }^{18} \quad 2021$ Among people living with HIV, this trend is magnified; as people living with HIV have disproportionately high chronic pain and opioid analgesic use, despite their elevated risk of opioid misuse and use disorder. ${ }^{6} 14$ 22-26 With concerns about opioid analgesic use and guidelines recommending non-opioid therapies, medical cannabis has emerged as an important treatment option. ${ }^{27}$ As of November 2020, 35 states and Washington, DC have legalised medical cannabis, with pain as the most common indication. ${ }^{28}$ 
Cannabis contains more than 60 active cannabinoids; the two most active in cannabinoid receptor activation are $\Delta$ 9-tetrahydrocannabinol (THC) and cannabidiol (CBD) ${ }^{29}$ The main psychotropic cannabinoid in cannabis, THC, can produce euphoria or anxiety, along with having an effect on pain and other symptoms. ${ }^{29} \mathrm{CBD}$ is non-psychoactive and also has analgesic, anti-inflammatory, antioxidant, anticonvulsant and anxiolytic effects. ${ }^{29}$ A combination of THC and CBD may be more effective in treating pain than THC alone, as CBD appears to both potentiate and block particular pharmacological effects of THC. ${ }^{30-34}$

Numerous short-term randomised controlled trials have demonstrated that compared with placebo, cannabis use reduces pain. ${ }^{35-49}$ In 2017, a landmark review found 'conclusive or substantial evidence' that cannabis is effective in treating chronic pain. ${ }^{50}$ While existing randomised controlled trials provide evidence about the effect of cannabis on pain, they were short term, and only one included products with different THC/CBD content. ${ }^{45}$ Importantly, they did not examine the relationship between cannabis and opioid analgesic use.

Limited evidence from cross-sectional and ecological studies suggests that cannabis use is associated with reduced opioid analgesic use. In several cross-sectional surveys, patients taking medical cannabis reported taking less opioid analgesics after using medical cannabis or substituting it for opioid analgesics. ${ }^{51-56}$ In population-level studies through 2013, medical cannabis availability was associated with lower rates of opioid analgesic prescription and lower rates of fatal opioid overdoses. ${ }^{578}$ To fully understand the potential implications of medical cannabis legalisation on the opioid epidemic, longitudinal studies that focus on patient-level opioid analgesic use are necessary.

Cannabis use is common in people living with HIV and can impact HIV outcomes through a variety of mechanisms. ${ }^{59-68}$ Studies examining the relationship between cannabis use and HIV outcomes have had conflicting results in terms of HIV viral load, CD4 count and antiretroviral adherence. ${ }^{59} 63$ 69-78 However, one consistent finding is cannabis's association with high-risk behaviours for HIV transmission. ${ }^{62} 79-83$ No studies have examined how products with different THC/CBD content affect HIV outcomes.

In addition to potential benefits of cannabis, there is evidence of adverse events. ${ }^{84}$ Important potential adverse events are cannabis use disorder, illicit drug use, diversion (selling or sharing medical cannabis), overdose or death, accidents or injuries, and acute healthcare utilisation. Cannabis use is associated with motor vehicle accidents, poor driving performance, injuries and increased hospitalisations. ${ }^{84-92}$ Many studies report these adverse events among individuals using illicit cannabis short term; but, few examine adverse events among those using medical cannabis long term. To our knowledge, no studies have prospectively examined these adverse events after initiating medical cannabis.

Medical cannabis policies differ by state, and New York's (NY) medical cannabis programme is one of the most stringent. ${ }^{93}$ To be certified for medical cannabis, individuals must have at least one qualifying condition (cancer, HIV infection or AIDS, amyotrophic lateral sclerosis, Parkinson's disease, multiple sclerosis, spinal cord injury with spasticity, epilepsy, inflammatory bowel disease, neuropathy, Huntington's disease, post-traumatic stress disorder, chronic pain, pain that degrades health and functional capability as an alternative to opioid use, or substance use disorder) and at least one complication (severe or chronic pain resulting in substantial limitation of function, cachexia or wasting syndrome, severe nausea, seizures, severe or persistent muscle spasms, post-traumatic stress disorder or opioid use disorder). Medical cannabis products must be purchased from a state-licensed dispensary which have pharmacists on-site, companies must offer products with a variety of THC and CBD content, and all products are tested by an independent lab to confirm content. Dispensaries upload records of all medical cannabis products dispensed to the NY Prescription Monitoring Program (PMP). Despite states' widespread legalised medical cannabis policies, at the federal level, cannabis remains classified as a Schedule 1 substance with 'no currently accepted medical use and a high potential for abuse' ${ }^{94}$ Because of this classification, federally funded cannabis research is extremely restricted.$^{50}$ From a clinical perspective, physicians cannot prescribe medical cannabis like other medications; they can only certify patients to purchase it. In NY, unless providers recommend a specific dose or type of product, patients can choose THC/CBD content, dose, amount and route of administration.

Because chronic pain is common and difficult to manage, non-opioid pain management strategies are recommended, and legalised medical cannabis use continues to grow, the goal of our longitudinal cohort study is to improve understanding of how medical cannabis use affects opioid analgesic use over time, with particular attention to THC/CBD content, HIV outcomes and adverse events. We hypothesise that: (1) medical cannabis use will be associated with a reduction in opioid analgesic use; (2) the association between medical cannabis and opioid analgesic use will differ by THC/CBD content; (3) HIV outcomes (viral load, CD4 count, antiretroviral adherence and risk behaviours) will differ by medical cannabis use and THC/CBD content; and (4) more medical cannabis use and higher THC (vs CBD) content will be associated with more adverse events (cannabis use disorder, illicit drug use, diversion, overdose/death, accidents/injuries, hospitalisations/emergency room visits). Here, we describe the protocol of our longitudinal cohort study to test these hypotheses.

\section{METHODS AND ANALYSES \\ Settings}

Recruitment and study visits occur at Montefiore Medical Center (Montefiore) and four medical cannabis dispensaries. Montefiore is the largest healthcare system in the Bronx, NY with primary, specialty, surgical and acute care at 4 hospitals, 4 emergency rooms and over 20 clinics. 
We collaborate with four medical cannabis dispensaries in the New York City (NYC) area, which are operated by Vireo Health and Columbia Care and provide services to over 30000 patients.

\section{Study participants}

Inclusion criteria are: (1) >18 years old, (2) fluency in English or Spanish, (3) new certification for medical cannabis within 90 days, (4) no medical cannabis use in the 6 months prior to certification, (5) medical cannabis qualifying condition of 'chronic pain', or 'pain that degrades health and functional capability as an alternative to opioid use' or qualifying complication of 'severe or chronic pain resulting in substantial limitation of function,' and (6) use of prescribed or illicit opioids within 30 days.

Exclusion criteria are: (1) inability to provide informed consent, (2) inability to complete study visits over 18 months, (3) qualifying conditions for medical cannabis in NY that are likely to cause unique pain syndromes (cancer, epilepsy, multiple sclerosis, spinal cord injury, amyotrophic lateral sclerosis, Parkinson's disease, inflammatory bowel disease, Huntington's disease), (4) terminal illness, and (5) current or prior psychotic disorder. Inclusion criteria \#3-5, and exclusion criterion \#3 are from medical or PMP data.

\section{Recruitment}

Our target enrolment is based on HIV status (target: 62 adults with HIV infection and 188 adults without HIV infection). On 14 September 2018, we began recruiting participants via: (1) providers at Montefiore and medical cannabis dispensaries informing patients about the study during certification or initial appointments, (2) letters mailed to potential participants who were identified in medical records with new medical cannabis certification, (3) flyers posted in facilities and websites.

\section{Research visits}

Participants have seven in-person research visits at $0,3,6$, $9,12,15$ and 18 months. At the enrolment visit, study staff describe the study and obtain written informed consent. Tracking forms and agreements to release medical, pharmacy and PMP records are completed. Participants receive a refillable debit card for compensation. At all in-person visits, we administer questionnaires, extract PMP records, and collect urine and blood samples (depending on HIV status). We obtain medical and pharmacy records at 0,6 , 12 and 18 months. Participants receive $\$ 40$ for in-person research visits (60-90 $\mathrm{min})$ and up to $\$ 5.50$ for transportation costs, which is equivalent to round-trip fare on NYC public transit.

In addition to in-person visits, participants complete 39 brief (2-5 min) web-based questionnaires every 2 weeks. At the baseline visit, participants are trained to access and complete web-based questionnaires on cellphones. If participants have discomfort with or poor access to the internet, they can complete the questionnaires via voice phone calls with study staff. After completing each web-based questionnaire, $\$ 5$ is deposited into participants' debit card. If all web-based questionnaires are completed between each in-person visit, a $\$ 10$ bonus is provided.

\section{Data sources and collection \\ Questionnaires}

At all in-person research visits that occur every 3 months, study staff administer questionnaires using Audio Computer-Assisted Self-Interview (ACASI) technology. The ACASI system displays questions on a computer while playing an audio recording of the question. Participants enter responses onto the computer.

For web-based questionnaires that occur every 2 weeks, participants receive personalised links to a web-based questionnaire from TelASK Technologies (Nepean, Ontario, Canada). Participants choose how (text or email) and when (day of the week and time) to receive automated links. Web-based questionnaires focus on pain, medical and illicit cannabis use, and prescribed and illicit opioid analgesic use during the previous 2 weeks.

\section{Medical record data}

We extract medical record data from medical facilities that participants visited 6 months prior to enrolment through 18 months after enrolment. Data include medical cannabis certification forms, lab values, prescriptions and notes regarding pain treatment.

\section{Pharmacy and PMP records}

We extract medications dispensed 6 months prior to enrolment through 18 months after enrolment. From pharmacy records, we extract medication data for all HIV medications and all pain medications. From PMP records, we extract medication data for all controlled substances, including medical cannabis and opioid analgesics.

\section{Urine toxicology tests}

At all in-person visits, we collect unobserved urine specimens. Urine is tested for cannabinoids, opiates, oxycodone, methadone, buprenorphine, benzodiazepines and cocaine using an enzyme immunoassay test (RapidTox8 from American Bio Medica Corporation, Kinderhook, New York, USA).

\section{HIV tests and labs}

Among participants with HIV infection, we collect blood every 6 months to measure HIV viral load (Abbott RealTime HIV-1 Assay from Abbott Laboratories, Abbott Park, Illinois, USA) and CD4 counts (AQUIOS CL flow cytometer from Beckman Coulter Life Sciences, Indianapolis, Indiana, USA), which are processed at Montefiore's central lab. In addition, at the baseline visit, we offer all participants rapid HIV tests (OraQuick ADVANCE Rapid HIV-1/2 Antibody Test from OraSure Technologies, Bethlehem, Pennsylvania, USA). 


\section{Physical function tests}

At all in-person visits, participants perform three standardised exercises-10-Metre Walk Test, ${ }^{96-99}$ Chair Stand Test ${ }^{100101}$ and Fingertip-to-Floor Test. ${ }^{102}$ With the 10-Metre Walk Test, we record the amount of time it takes participants to walk $10 \mathrm{~m}$ two times, with the assistance of any device (eg, walking cane) that the participant normally uses. With the Chair Stand Test, over a 30-second period, we record the number of times that participants are able to stand from a seated position. For the Fingertip-to-Floor Test, after participants bend over from a standing position towards the floor, we measure the distance between participants' fingertips and floor. All are reliable, valid and responsive measures of physical function in patients with chronic pain conditions including low back pain, arthritis and neuropathy, and are simple to administer in a clinical setting. ${ }^{103}$

\section{Key variables}

\section{Main exposure variable}

Our main exposure variable is medical cannabis use and is measured by combining PMP and questionnaire data. PMP data include: date, product (which specifies THC/ CBD content), dose, formulation, route, directions, amount dispensed and dispensary. Web-based questionnaires inquire about both medical and illicit cannabis use for every 2-week period. For medical cannabis use, participants are asked: number of days used, medical cannabis product (which specifies THC/CBD content and formulation), route and amount used on a typical day. For illicit cannabis use, participants are asked: number of days used, dollar amount of cannabis purchased, route, type of cannabis and amount used on a typical day.

For each of the 39 2-week periods, our primary measure of exposure to medical cannabis is number of days of medical cannabis use. Alternate measures are number of days of medical and illicit cannabis use, cumulative dose of THC and cumulative dose of CBD.

\section{Primary outcome variable}

Opioid analgesic use is the primary outcome and is measured by combining prescribed and illicit opioid analgesic use from the PMP and web-based questionnaires. Our primary measure of opioid analgesic use is cumulative dose of all opioid analgesics over each of the 39 2-week periods (in morphine milligram equivalents (MME)). Alternative measures are number of days of all opioid analgesic use, mean daily dose (in MME) of all opioid analgesics and number of days of only prescribed (not illicit) opioid analgesics (all continuous measures).

\section{Secondary outcome variables}

HIV outcomes are examined in the subgroup of participants with HIV infection. Viral load is the main HIV outcome, and the primary measure is $\log 10$ copies $/ \mathrm{mL}$. CD4 count is analysed as cells $/ \mathrm{mm}^{3}$. Viral load and CD4 count are measured from study blood samples every 6 months. Antiretroviral adherence is analysed using the proportion of days in which antiretroviral medications are filled (pharmacy records) and self-reported adherence. ${ }^{104} 105$ HIV risk behaviours are measured using the HIV Risk-taking Behaviour Scale. ${ }^{106-108}$

Several adverse events are secondary outcomes. Cannabis use disorder is assessed using the MiniInternational Neuropsychiatric Interview. ${ }^{109}$ Illicit drug use is measured using the Addiction Severity Index ${ }^{10}$ and urine toxicology tests. Diversion of medical cannabis is measured using a modified version of the Massachusetts General Hospital Medication Questionnaire. ${ }^{111}$ Nonfatal overdose is measured using items on the Addiction Severity Index; death is ascertained from the National Death Index. Accidents/injuries are measured using questions from national surveys in the USA and Canada. ${ }^{112} 113$ Acute healthcare utilisation (hospitalisations and emergency room visits) is self-reported using the National Institute on Drug Abuse data harmonisation instrument.

\section{Other key variables}

Other key variables that are potential confounders include sociodemographic characteristics, pain severity and interference, ${ }^{114}$ pain catastrophising, ${ }^{115}$ pain-related function and disability, ${ }^{116}$ pain treatment, alcohol use, ${ }^{117}$ tobacco use, ${ }^{118}$ other substance use, ${ }^{110}$ symptoms of depression, ${ }^{119}$ anxiety, ${ }^{120}$ post-traumatic stress disorder, ${ }^{121}{ }^{122}$ attention deficit hyperactivity disorder, ${ }^{123}$ insomnia, ${ }^{124}$ physical functional tests and quality of life. ${ }^{125}$

\section{Data analyses}

Participants' 39 assessments for each 2-week time period is the unit of analysis. We will determine the association between medical cannabis use (exposure) and opioid analgesic use (outcome) using marginal structural models. Marginal structural models are necessary because they can account for time-varying confounding (ie, variables that are both predictors of the subsequent outcome and subsequent exposure). ${ }^{126} 127$ Consistent with the steps of marginal structural models, we will first calculate inverse probability-of-exposure weights for each participant's 2-week time period. Calculation of these weights is based on the predicted probability of the exposure in each of the 39 2-week time periods, given time-invariant and timevarying confounders. After calculation of weights, we will create the main marginal structural model-a linear generalised estimating equations model for repeated measures on a natural logarithm scale, incorporating weights, accounting for clustering within participants and estimating robust SEs. ${ }^{126}$

In our main analysis, we will examine whether medical cannabis use is associated with reductions in opioid analgesic use. We will also conduct sensitivity analyses to determine robustness of our findings to different specifications of the weighting model. ${ }^{128}$ We will also conduct simulation analyses to determine the robustness of our findings to potential unmeasured confounders. ${ }^{129}$ Finally, we will repeat our model-building processes using alternative 
measures of medical cannabis and opioid analgesic use as described above.

In one set of secondary analyses, we will determine the association between THC and CBD and opioid analgesic use, using similar marginal structural models as described above. However, in one model, the exposure will be cumulative dose of THC in each 2-week period, and in the other model the exposure will be cumulative dose of CBD in each 2-week period. To determine the effects of cumulative THC and CBD dose together, we will use a joint marginal structural model. ${ }^{130}{ }^{131}$ We will multiply the estimated stabilised weights for THC by the estimated stabilised weights for CBD to produce a joint weight. To analyse this, we will visually plot combinations of cumulative THC and CBD doses and the expected change in cumulative opioid analgesic dose, accounting for the interaction between THC and CBD.

In the second set of secondary analyses, we will examine the effect of medical cannabis use, THC content and CBD content use on HIV outcomes (viral load, CD4 count, antiretroviral adherence, risk behaviours). Because time-dependent confounding is not a problem for HIV outcomes, we will use standard mixed-effects regression models with generalised estimating equations, with a working first-order autoregressive covariance matrix and robust estimates of variance. Because HIV viral load will be measured every 6 months, a 6 -month time period is the unit of analysis.

In the third set of secondary analyses, we will examine the effect of medical cannabis use, THC content and CBD content on adverse events (cannabis use disorder, illicit drug use, diversion of medical cannabis, overdose/death, accidents/injuries, and hospitalisations and emergency room visits). Depending on whether the adverse event is dichotomous (eg, cannabis use disorder) or continuous (eg, number of hospitalisations), we will use similar marginal structural models as described above using separate logistic or linear marginal structural models for each adverse event.

\section{Sample size}

We estimated the sample size needed to detect a $0.5 \%$ change in cumulative opioid analgesic dose with one additional day of medical cannabis. We chose this value because 14 days of medical cannabis use would then be associated with a $7 \%$ change in cumulative opioid analgesic dose over 2 weeks. This degree of dosage reduction is within the range of what is considered clinically meaningful. ${ }^{27}$ To estimate our sample size, we used linear mixed-effects models with simulations repeated 1000 times. Accounting for $20 \%$ attrition, 250 is the target sample size, as a sample size of 200 can detect associations between medical cannabis use and the outcome greater than $90 \%$ of the time. We selected a sample size with a higher power than typically chosen to ensure sufficient sample for the marginal structural model which includes several variables representing time-dependent confounding.
For HIV outcomes, we calculated power based on $\log 10$ viral load (main HIV outcome). With viral load measured every 6 months and a sample of $50 \mathrm{HIV}+$ participants, we would have greater than $99 \%$ power to detect a change of $0.5 \log 10$ viral load. With $20 \%$ attrition, we will enrol 62 HIV+ participants. For adverse events, we calculated power based on illicit drug use as the main outcome measure (continuous measure from the Addiction Severity Index alcohol/drug subscale). A sample size of 200 participants would have greater than $99 \%$ power to detect a $5 \%$ change in the continuous subscale measure.

\section{Timeline and monitoring}

We began enrolling participants on 14 September 2018. We anticipate that enrolment will be completed by 31 December 2021, and study visits will conclude on 30 June 2023. The principal investigator oversees data and safety monitoring, including review of protocol deviations and submission of annual reports to the affiliated institutional review board (IRB) and funder (National Institute of Health). Because the study is observational and therefore minimal risk, we did not establish a formal data and safety monitoring board, nor will we conduct interim analyses with stopping rules.

\section{Limitations}

As a longitudinal cohort study, this study has limitations. Because of federal cannabis policies in the USA, cannabis is extremely restricted in federal research. Therefore, it is not feasible to use a randomised controlled trial design and administer cannabis to 250 participants over 18 months. By using advanced analytical methods that exploit variation in medical cannabis products and patterns of use, we will estimate the impact of medical cannabis use on opioid analgesic use. While our study design and analytical approach will improve our understanding of how medical cannabis use affects opioid analgesic use, we will be unable to account for all potential biases, and we are limited to conducting analyses within, instead of between, participants. In addition, because adults with HIV infection may have unique pain conditions, to determine if including participants with HIV infection in the sample leads to differences in findings, we will conduct two sets of main analyses-one including participants with HIV infection, and one excluding participants with HIV infection. While our study will examine a range of potential adverse events from medical cannabis use, it does not examine all potential adverse events, including neurocognitive changes. Finally, because opioid prescription in the USA has decreased over the past several years, ${ }^{132}$ it is possible that further decreases in opioid prescription may make it difficult to interpret the relationship between medical cannabis and opioid use.

\section{Patient and public involvement}

The design of this study was informed by clinical experiences of several of the authors, along with our prior study examining potential interest in participating in a 
medical cannabis research study among adults receiving medical cannabis. ${ }^{133}$ The research questions and design were reviewed by physician-investigators at Montefiore Medical Center/Albert Einstein College of Medicine who have expertise in substance use and infectious diseases, along with chief medical officers of two medical cannabis companies. In addition, the research questions and design were reviewed by a study section at the National Institute of Health.

\section{Ethics and dissemination}

This study was approved by the Montefiore Medical Center/Albert Einstein College of Medicine IRB (IRB protocol number: 2017-7857). Oral informed consent is obtained prior to conducting screening questionnaires, and written informed consent is obtained at the time of enrolment into the study. Several steps are taken to protect participant confidentiality, including using a data management system that separates 'name-based' and 'study ID-based' documents, obtaining a Certificate of Confidentiality from the National Institute of Health, and using a two-step verification process to access the study database.

We will disseminate study findings through presentations at scientific conferences, publications in peerreviewed journals and presentations to medical cannabis stakeholders. Study findings will be reported in accordance with the Strengthening the Reporting of Observational Studies in Epidemiology Statement. ${ }^{134}$

\section{Author affiliations}

${ }^{1}$ Division of General Internal Medicine, Montefiore Health System, Bronx, New York, USA

${ }^{2}$ Section of Community and Population Medicine, Louisiana State University Health Sciences Center, New Orleans, Louisiana, USA

${ }^{3}$ School of Medicine, City University of New York, New York, New York, USA ${ }^{4}$ Department of Psychiatry, Columbia University Irving Medical Center, New York, New York, USA

${ }^{5}$ Psychology Department, Fordham University, Bronx, New York, USA

\section{Twitter Chinazo 0 Cunningham @DrChinazo}

Contributors $\mathrm{COC}$ is the principal investigator of this study and led its conception and design. JS, CZ, MB, NS, FRL, HM and JA made substantial contributions to the conception and design of the study. COC drafted the manuscript, and all authors revised it for critically important content (COC, JS, CA, MB, NS, FRL, HM, DS and JA). All authors (COC, JS, CA, MB, NS, FRL, HM, DS and JA) provided final approval of the manuscript.

Funding This study is supported by the National Institute on Drug Abuse of the National Institute of Health (R01DA044171). COC and JS are also supported by the National Institute on Drug Abuse (K24DA036955, K24DA046309). COC and JA are also supported by the National Institute of Allergy and Infectious Diseases of the National Institute of Health (P30Al124414).

Disclaimer The content is solely the responsibility of the authors and does not represent the official views of the National Institute of Health. The funding agency has no role in design or conduct of the study, or the decision to publish study results.

\section{Competing interests None declared.}

Patient and public involvement Patients and/or the public were not involved in the design, or conduct, or reporting, or dissemination plans of this research.

Patient consent for publication Not required.

Provenance and peer review Not commissioned; externally peer reviewed.
Open access This is an open access article distributed in accordance with the Creative Commons Attribution Non Commercial (CC BY-NC 4.0) license, which permits others to distribute, remix, adapt, build upon this work non-commercially, and license their derivative works on different terms, provided the original work is properly cited, appropriate credit is given, any changes made indicated, and the use is non-commercial. See: http://creativecommons.org/licenses/by-nc/4.0/.

ORCID iD

Chinazo 0 Cunningham http://orcid.org/0000-0002-7930-313X

\section{REFERENCES}

1 Johannes CB, Le TK, Zhou X, et al. The prevalence of chronic pain in United States adults: results of an Internet-based survey. $J$ Pain 2010;11:1230-9.

2 Breitbart W, Dibiase L. Current perspectives on pain in AIDS. Oncology 2002;16:964-8.

3 Hewitt DJ, McDonald M, Portenoy RK, et al. Pain syndromes and etiologies in ambulatory AIDS patients. Pain 1997;70:117-23.

4 Perry BA, Westfall AO, Molony E, et al. Characteristics of an ambulatory palliative care clinic for HIV-infected patients. J Palliat Med 2013;16:934-7.

5 Koeppe J, Lyda K, Armon C. Association between opioid use and health care utilization as measured by emergency room visits and hospitalizations among persons living with HIV. Clin J Pain 2013;29:957-61.

6 Tsao JCl, Dobalian A, Naliboff BD. Panic disorder and pain in a national sample of persons living with HIV. Pain 2004;109:172-80.

7 Larue F, Fontaine A, Colleau SM. Underestimation and undertreatment of pain in HIV disease: multicentre study. BMJ 1997;314:23-8.

8 Frich LM, Borgbjerg FM. Pain and pain treatment in AIDS patients: a longitudinal study. J Pain Symptom Manage 2000;19:339-47.

9 Tsao JCl, Stein JA, Dobalian A. Pain, problem drug use history, and aberrant analgesic use behaviors in persons living with HIV. Pain 2007;133:128-37.

10 Dobalian A, Tsao JCl, Duncan RP. Pain and the use of outpatient services among persons with HIV: results from a nationally representative survey. Med Care 2004;42:129-38.

11 Tsao JCl, Plankey MW, Young MA. Pain, psychological symptoms and prescription drug misuse in HIV: a literature review. J Pain Manag 2012;5:111-8.

12 Breitbart W, McDonald MV, Rosenfeld B, et al. Pain in ambulatory AIDS patients. I: pain characteristics and medical correlates. Pain 1996;68:315-21.

13 Radin Kimball L, McCormick WC. The pharmacologic management of pain and discomport in persons with AIDS near the end of life: use of opioid analgesia in the hospice setting. J Pain Symptom Manage 1996;11:88-94.

14 Edelman EJ, Gordon K, Becker WC, et al. Receipt of opioid analgesics by HIV-infected and uninfected patients. J Gen Intern Med 2013;28:82-90.

15 Simmonds MJ, Novy D, Sandoval R. The differential influence of pain and fatigue on physical performance and health status in ambulatory patients with human immunodeficiency virus. Clin $\mathrm{J}$ Pain 2005;21:200-6.

16 Singer EJ, Zorilla C, Fahy-Chandon B, et al. Painful symptoms reported by ambulatory HIV-infected men in a longitudinal study. Pain 1993;54:15-19.

17 Merlin JS, Westfall AO, Raper JL, et al. Pain, mood, and substance abuse in HIV: implications for clinic visit utilization, antiretroviral therapy adherence, and virologic failure. J Acquir Immune Defic Syndr 2012;61:164-70.

18 Centers for Disease Control and Prevention (CDC). Vital signs: overdoses of prescription opioid pain relievers---United States, 1999--2008. MMWR Morb Mortal Wkly Rep 2011;60:1487-92.

19 Kenan K, Mack K, Paulozzi L. Trends in prescriptions for oxycodone and other commonly used opioids in the United States, 2000-2010. Open Med 2012;6:e41-7.

20 Atluri S, Sudarshan G, Manchikanti L. Assessment of the trends in medical use and misuse of opioid analgesics from 2004 to 2011. Pain Physician 2014;17:E119-28.

21 Modarai F, Mack K, Hicks P, et al. Relationship of opioid prescription sales and overdoses, North Carolina. Drug Alcohol Depend 2013;132:81-6.

22 Silverberg MJ, Ray GT, Saunders K, et al. Prescription long-term opioid use in HIV-infected patients. Clin J Pain 2012;28:39-46.

23 Tsao JCl, Dobalian A, Moreau C, et al. Stability of anxiety and depression in a national sample of adults with human immunodeficiency virus. J Nerv Ment Dis 2004;192:111-8. 
24 Koeppe J, Armon C, Lyda K, et al. Ongoing pain despite aggressive opioid pain management among persons with HIV. Clin J Pain 2010;26:190-8.

25 Vitiello B, Burnam MA, Bing EG, et al. Use of psychotropic medications among HIV-infected patients in the United States. Am $J$ Psychiatry 2003;160:547-54.

26 Jeevanjee S, Penko J, Guzman D, et al. Opioid analgesic misuse is associated with incomplete antiretroviral adherence in a cohort of HIV-infected indigent adults in San Francisco. AIDS Behav 2014:18:1352-8.

27 Dowell D, Haegerich TM, Chou R. Cdc guideline for prescribing opioids for chronic pain - United States, 2016. MMWR Recomm. Rep. 2016;65:1-49.

28 ProCon.org. 28 legal medical marijuana states and DC. Available: https://medicalmarijuana.procon.org/legal-medical-marijuanastates-and-dc/ [Accessed 28 Nov 2020].

29 Pertwee RG, Howlett AC, Abood ME, et al. International Union of basic and clinical pharmacology. LXXIX. cannabinoid receptors and their ligands: beyond $\mathrm{CB}_{1}$ and $\mathrm{CB}_{2}$. Pharmacol Rev 2010;62:588-631.

30 Hayakawa K, Mishima K, Hazekawa M, et al. Cannabidiol potentiates pharmacological effects of Delta(9)tetrahydrocannabinol via $\mathrm{CB}(1)$ receptor-dependent mechanism. Brain Res 2008;1188:157-64.

31 Varvel SA, Wiley JL, Yang R, et al. Interactions between THC and cannabidiol in mouse models of cannabinoid activity. Psychopharmacology 2006;186:226-34.

32 Karniol IG, Shirakawa I, Kasinski N, et al. Cannabidiol interferes with the effects of $\Delta 9$-tetrahydrocannabinol in man. Eur J Pharmacol 1974;28:172-7.

33 Johnson JR, Burnell-Nugent M, Lossignol D, et al. Multicenter, Double-Blind, Randomized, Placebo-Controlled, Parallel-Group Study of the Efficacy, Safety, and Tolerability of THC:CBD Extract and THC Extract in Patients with Intractable Cancer-Related Pain. $J$ Pain Symptom Manage 2010;39:167-79.

34 Russo E, Guy GW. A tale of two cannabinoids: the therapeutic rationale for combining tetrahydrocannabinol and cannabidiol. Med Hypotheses 2006;66:234-46.

35 Whiting PF, Wolff RF, Deshpande S, et al. Cannabinoids for medical use: a systematic review and meta-analysis. JAMA 2015;313:2456-73.

36 Ellis RJ, Toperoff W, Vaida F, et al. Smoked medicinal cannabis for neuropathic pain in HIV: a randomized, crossover clinical trial. Neuropsychopharmacology 2009;34:672-80.

37 Nurmikko TJ, Serpell MG, Hoggart B, et al. Sativex successfully treats neuropathic pain characterised by allodynia: a randomised, double-blind, placebo-controlled clinical trial. Pain 2007;133:210-20.

38 Abrams DI, Jay CA, Shade SB, et al. Cannabis in painful HIVassociated sensory neuropathy: a randomized placebo-controlled trial. Neurology 2007;68:515-21.

39 Wilsey B, Marcotte T, Tsodikov A, et al. A randomized, placebocontrolled, crossover trial of cannabis cigarettes in neuropathic pain. J Pain 2008:9:506-21.

40 Skrabek RQ, Galimova L, Ethans K, et al. Nabilone for the treatment of pain in fibromyalgia. J Pain 2008;9:164-73.

41 Narang S, Gibson D, Wasan AD, et al. Efficacy of dronabinol as an adjuvant treatment for chronic pain patients on opioid therapy. $J$ Pain 2008;9:254-64.

42 Wissel J, Haydn T, Müller J, et al. Low dose treatment with the synthetic cannabinoid Nabilone significantly reduces spasticityrelated pain : a double-blind placebo-controlled cross-over trial. J Neurol 2006;253:1337-41.

43 Blake DR, Robson P, Ho M, et al. Preliminary assessment of the efficacy, tolerability and safety of a cannabis-based medicine (Sativex) in the treatment of pain caused by rheumatoid arthritis. Rheumatology 2006;45:50-2.

44 Hill KP. Medical marijuana for treatment of chronic pain and other medical and psychiatric problems. JAMA 2015;313:2474-83.

45 Berman JS, Symonds C, Birch R. Efficacy of two cannabis based medicinal extracts for relief of central neuropathic pain from brachial plexus avulsion: results of a randomised controlled trial. Pain 2004;112:299-306.

46 Andreae MH, Carter GM, Shaparin N, et al. Inhaled cannabis for chronic neuropathic pain: a meta-analysis of individual patient data. J Pain 2015;16:1221-32.

47 Karst M, Salim K, Burstein S. Analgesic effect of the synthetic cannabinoid CT-3 on chronic neuropathic pain: a randomized controlled trial. JAMA 2003;290:1757-62.

48 Langford RM, Mares J, Novotna A, et al. A double-blind, randomized, placebo-controlled, parallel-group study of $\mathrm{THC}$
CBD oromucosal spray in combination with the existing treatment regimen, in the relief of central neuropathic pain in patients with multiple sclerosis. J Neurol 2013;260:984-97.

49 Rog DJ, Nurmikko TJ, Friede T, et al. Randomized, controlled tria of cannabis-based medicine in central pain in multiple sclerosis. Neurology 2005;65:812-9.

50 National Academies of Sciences, Engineering, and Medicine. The health effects of cannabis and cannabinoids: the current state of evidence and recommendations for research. Washington, DC: The National Academies Press, 2017.

51 Grella CE, Rodriguez L, Kim T. Patterns of medical marijuana use among individuals sampled from medical marijuana dispensaries in Los Angeles. J Psychoactive Drugs 2014;46:263-72.

52 Reiman A. Cannabis as a substitute for alcohol and other drugs. Harm Reduct J 2009;6:35.

53 Nunberg H, Kilmer B, Pacula RL, et al. An analysis of applicants presenting to a medical marijuana specialty practice in California. $J$ Drug Policy Anal 2011;4.

54 Zaller N, Topletz A, Frater S, et al. Profiles of medicinal cannabis patients attending compassion centers in Rhode island. $J$ Psychoactive Drugs 2015;47:18-23.

55 Boehnke KF, Litinas E, Clauw DJ. Medical cannabis use is associated with decreased opiate medication use in a retrospective cross-sectional survey of patients with chronic pain. J Pain 2016;17:739-44.

56 Sohler NL, Starrels JL, Khalid L, et al. Cannabis use is associated with lower odds of prescription opioid analgesic use among HIV-infected individuals with chronic pain. Subst Use Misuse 2018;53:1602-7.

57 Bachhuber MA, Saloner B, Cunningham CO, et al. Medical cannabis laws and opioid analgesic overdose mortality in the United States, 1999-2010. JAMA Intern Med 2014;174:1668-73.

58 Bachhuber MA, Saloner B, Cunningham CO. Could Delaware's medical marijuana law reduce harms from opioid analgesics? Del Med J 2014;86:341-3.

59 D'souza G, Matson PA, Grady CD, et al. Medicinal and recreational marijuana use among HIV-infected women in the women's Interagency HIV study (WIHS) cohort, 1994-2010. J Acquir Immune Defic Syndr 2012;61:618-26.

60 Bruce D, Harper GW, Fernandez MI, et al. Heavy marijuana use among gay and bisexual male emerging adults living with HIV/AIDS. J HIV AIDS Soc Serv 2013;12:26-48.

61 Prentiss D, Power R, Balmas G, et al. Patterns of marijuana use among patients with HIV/AIDS followed in a public health care setting. J Acquir Immune Defic Syndr 2004;35:38-45.

62 Mimiaga MJ, Reisner SL, Grasso C, et al. Substance use among HIV-infected patients engaged in primary care in the United States: findings from the centers for AIDS research network of integrated clinical systems cohort. Am J Public Health 2013:103:1457-67.

63 Furler MD, Einarson TR, Millson M, et al. Medicinal and recreational marijuana use by patients infected with HIV. AIDS Patient Care STDS 2004:18:215-28.

64 Okafor CN, Cook RL, Chen X, et al. Trajectories of marijuana use among HIV-seropositive and HIV-seronegative MSM in the Multicenter AIDS cohort study (MACS), 1984-2013. AIDS Behav 2017;21:1091-104.

65 Ompad DC, Giobazolia TT, Barton SC, et al. Drug use among HIV+ adults aged 50 and older: findings from the gold II study. AIDS Care 2016;28:1373-7.

66 Friedman $\mathrm{H}$, Klein TW, Newton $\mathrm{C}$, et al. Marijuana, receptors and immunomodulation. Adv Exp Med Biol 1995;373:103-13.

67 Nahas GG, Suciu-Foca N, Armand J-P, et al. Inhibition of cellular mediated immunity in marihuana smokers. Science 1974;183:419-20.

68 Hollister LE. Marijuana and immunity. J Psychoactive Drugs 1992;24:159-64.

69 Milloy M-J, Marshall B, Kerr T, et al. High-Intensity cannabis use associated with lower plasma human immunodeficiency virus-1 RNA viral load among recently infected people who use injection drugs. Drug Alcohol Rev 2015;34:135-40.

70 Ghosn J, Leruez-Ville M, Blanche J, et al. Hiv-1 DNA levels in peripheral blood mononuclear cells and cannabis use are associated with intermittent HIV shedding in semen of men who have sex with men on successful antiretroviral regimens. Clin Infect Dis 2014;58:1763-70.

71 Abrams DI, Hilton JF, Leiser RJ, et al. Short-Term effects of cannabinoids in patients with HIV-1 infection: a randomized placebo-controlled clinical trial. Ann Intern Med 2003;139:258-66.

72 Bredt BM, Higuera-Alhino D, Shade SB, et al. Short-Term effects of cannabinoids on immune phenotype and function in HIV-1-infected patients. J Clin Pharmacol 2002;42:82S-9. 
73 Harris GE, Dupuis L, Mugford GJ, et al. Patterns and correlates of cannabis use among individuals with HIV/AIDS in maritime Canada. Can J Infect Dis Med Microbiol 2014;25:e1-7.

74 Slawson G, Milloy M-J, Balneaves L, et al. High-Intensity cannabis use and adherence to antiretroviral therapy among people who use illicit drugs in a Canadian setting. AIDS Behav 2015;19:120-7.

75 de Jong BC, Prentiss D, McFarland W, et al. Marijuana use and its association with adherence to antiretroviral therapy among HIVinfected persons with moderate to severe nausea. J Acquir Immune Defic Syndr 2005;38:43-6.

76 Bonn-Miller MO, Oser ML, Bucossi MM, et al. Cannabis use and HIV antiretroviral therapy adherence and HIV-related symptoms. $J$ Behav Med 2014;37:1-10.

77 Tucker JS, Burnam MA, Sherbourne CD, et al. Substance use and mental health correlates of nonadherence to antiretroviral medications in a sample of patients with human immunodeficiency virus infection. Am J Med 2003;114:573-80.

78 Wilson KJ, Doxanakis A, Fairley CK. Predictors for non-adherence to antiretroviral therapy. Sex Health 2004;1:251-7.

79 Morgan E, Skaathun B, Michaels S, et al. Marijuana use as a Sex-Drug is associated with HIV risk among black MSM and their network. AIDS Behav 2016;20:600-7.

80 Kelly JA, St Lawrence JS, Tarima SS, et al. Correlates of sexual HIV risk among African American men who have sex with men. Am J Public Health 2016:106:96-102.

81 Scivoletto S, Tsuji RK, Najjar Abdo CH, et al. Use of psychoactive substances and sexual risk behavior in adolescents. Subst Use Misuse 2002;37:381-98.

82 Bellis MA, Hughes K, Calafat A, et al. Sexual uses of alcohol and drugs and the associated health risks: a cross sectional study of young people in nine European cities. BMC Public Health 2008;8:155

83 Brodbeck J, Matter M, Moggi F. Association between cannabis use and sexual risk behavior among young heterosexual adults. AIDS Behav 2006;10:599-605.

84 Volkow ND, Baler RD, Compton WM, et al. Adverse health effects of marijuana use. N Engl J Med 2014;370:2219-27.

85 Hartman RL, Huestis MA. Cannabis effects on driving skills. Clin Chem 2013:59:478-92

86 Asbridge M, Poulin C, Donato A. Motor vehicle collision risk and driving under the influence of cannabis: evidence from adolescents in Atlantic Canada. Accid Anal Prev 2005;37:1025-34.

87 Li M-C, Brady JE, DiMaggio CJ, et al. Marijuana use and motor vehicle crashes. Epidemiol Rev 2012;34:65-72.

88 Asbridge M, Hayden JA, Cartwright JL. Acute cannabis consumption and motor vehicle collision risk: systematic review of observational studies and meta-analysis. BMJ 2012;344:e536.

89 Barrio G, Jiménez-Mejías E, Pulido J, et al. Association between cannabis use and non-traffic injuries. Accid Anal Prev 2012;47:172-6.

90 Patel R, Wilson R, Jackson R, et al. Association of cannabis use with hospital admission and antipsychotic treatment failure in first episode psychosis: an observational study. BMJ Open 2016;6:e009888.

91 Moore CL, Gidding HF, Jin F, et al. Patterns of drug use and drugrelated hospital admissions in HIV-positive and -negative gay and bisexual men. AIDS Behav 2016;20:2372-86.

92 Jouanjus E, Pourcel L, Saivin S, et al. Use of multiple sources and capture-recapture method to estimate the frequency of hospitalizations related to drug abuse. Pharmacoepidemiol Drug Saf 2012;21:733-41.

93 New York State Department of Health. New York state medical marijuana program, 2016. Available: https://www.health.ny.gov/ regulations/medical_marijuana/ [Accessed 30 Aug 2020].

94 United States Drug Enforcement Administration. Drug schedules. Available: https://www.dea.gov/druginfo/ds.shtml [Accessed 17 Jan 2020].

95 Nutt DJ, King LA, Nichols DE. Effects of schedule I drug laws on neuroscience research and treatment innovation. Nat Rev Neurosci 2013:14:577-85.

96 Wolf SL, Catlin PA, Gage K, et al. Establishing the reliability and validity of measurements of walking time using the Emory functional ambulation profile. Phys Ther 1999;79:1122-33.

97 Bohannon RW. Comfortable and maximum walking speed of adults aged 20-79 years: reference values and determinants. Age Ageing 1997;26:15-19.

98 Bohannon RW, Andrews AW, Thomas MW. Walking speed: reference values and correlates for older adults. J Orthop Sports Phys Ther 1996;24:86-90.

99 Bohannon RW, Williams Andrews A. Normal walking speed: a descriptive meta-analysis. Physiotherapy 2011;97:182-9.
100 Jones CJ, Rikli RE, Beam WC. A 30-S chair-stand test as a measure of lower body strength in community-residing older adults. Res $Q$ Exerc Sport 1999;70:113-9.

101 Gill SD, de Morton NA, Mc Burney H. An investigation of the validity of six measures of physical function in people awaiting joint replacement surgery of the hip or knee. Clin Rehabil 2012;26:945-51.

102 Perret C, Poiraudeau S, Fermanian J, et al. Validity, reliability, and responsiveness of the fingertip-to-floor test. Arch Phys Med Rehabil 2001;82:1566-70.

103 Bennell K, Dobson F, Hinman R. Measures of physical performance assessments: Self-Paced Walk Test (SPWT), Stair Climb Test (SCT), Six-Minute Walk Test (6MWT), Chair Stand Test (CST), Timed Up \& Go (TUG), Sock Test, Lift and Carry Test (LCT), and Car Task. Arthritis Care Res 2011;63:S350-70.

104 Chesney MA, Ickovics JR, Chambers DB, et al. Self-reported adherence to antiretroviral medications among participants in HIV clinical trials: the AACTG adherence instruments. Patient Care Committee \& Adherence Working Group of the Outcomes Committee of the Adult AIDS Clinical Trials Group (AACTG). AIDS Care 2000;12:255-66.

105 Berg KM, Wilson IB, Li X, et al. Comparison of antiretroviral adherence questions. AIDS Behav 2012;16:461-8.

106 Darke S, Hall W, Heather N, et al. The reliability and validity of a scale to measure HIV risk-taking behaviour among intravenous drug users. AIDS 1991;5:181-6.

107 Knight KR, Shade SB, Purcell DW, et al. Sexual transmission risk behavior reported among behaviorally bisexual HIV-positive injection drug-using men. J Acquir Immune Defic Syndr 2007;46 Suppl 2:S80-7.

108 Purcell DW, Parsons JT, Halkitis PN, et al. Substance use and sexual transmission risk behavior of HIV-positive men who have sex with men. J Subst Abuse 2001:13:185-200.

109 Sheehan DV, Lecrubier Y, Sheehan KH, et al. The Mini-International neuropsychiatric interview (M.I.N.I.): the development and validation of a structured diagnostic psychiatric interview for DSM-IV and ICD10. J Clin Psychiatry 1998;59 Suppl 20:34-57.

110 McLellan AT, Kushner H, Metzger D, et al. The fifth edition of the addiction severity index. J Subst Abuse Treat 1992;9:199-213.

111 Winhusen TM, Lewis DF, Riggs PD, et al. Subjective effects, misuse, and adverse effects of osmotic-release methylphenidate treatment in adolescent substance abusers with attention-deficit/hyperactivity disorder. J Child Adolesc Psychopharmacol 2011;21:455-63.

112 Prevention NCfHSCfDCa. National health interview survey, CAPI manual for NHIS field representatives, 2020.

113 Poulin C, MacNeil P, Mitic W. The validity of a province-wide student drug use survey: lessons in design. Can J Public Health 1993;84:259-64.

114 Keller S, Bann CM, Dodd SL, et al. Validity of the brief pain inventory for use in documenting the outcomes of patients with noncancer pain. Clin J Pain 2004;20:309-18.

115 Sullivan MJL, Bishop SR, Pivik J. The pain catastrophizing scale: development and validation. Psychol Assess 1995;7:524-32.

116 Stroud MW, McKnight PE, Jensen MP. Assessment of self-reported physical activity in patients with chronic pain: development of an abbreviated Roland-Morris disability scale. J Pain 2004;5:257-63.

117 Saunders JB, Aasland OG, Babor TF, et al. Development of the Alcohol Use Disorders Identification Test (AUDIT): WHO Collaborative Project on Early Detection of Persons with Harmful Alcohol Consumption--II. Addiction 1993;88:791-804.

118 Commerce USDo. Census Bureau (2016). National cancer Institute and food and drug administration co-sponsored tobacco use supplement to the current population survey, 2014-15. Available: https://cancercontrol.cancer.gov/brp/tcrb/tus-cps/

119 Kroenke K, Spitzer RL, Williams JB. The PHQ-9: validity of a brief depression severity measure. J Gen Intern Med 2001;16:606-13.

120 Spitzer RL, Kroenke K, Williams JBW, et al. A brief measure for assessing generalized anxiety disorder: the GAD-7. Arch Intern Med 2006;166:1092-7.

121 Lang AJ, Stein MB. An abbreviated PTSD checklist for use as a screening instrument in primary care. Behav Res Ther 2005;43:585-94.

122 Lang AJ, Laffaye C, Satz LE, et al. Sensitivity and specificity of the PTSD checklist in detecting PTSD in female veterans in primary care. J Trauma Stress 2003;16:257-64.

123 Ustun B, Adler LA, Rudin C, et al. The world Health organization adult attention-deficit/hyperactivity disorder self-report screening scale for DSM-5. JAMA Psychiatry 2017;74:520-6.

124 Morin CM, Belleville G, Bélanger L, et al. The insomnia severity index: psychometric indicators to detect insomnia cases and evaluate treatment response. Sleep 2011;34:601-8. 
125 EuroQol Group. EuroQol--a new facility for the measurement of health-related quality of life. Health Policy 1990;16:199-208.

126 Hernán MA, Brumback BA, Robins JM. Estimating the causal effect of zidovudine on CD4 count with a marginal structural model for repeated measures. Stat Med 2002;21:1689-709.

127 Robins JM, Hernán MA, Brumback B. Marginal structural models and causal inference in epidemiology. Epidemiology 2000;11:550-60.

128 Cole SR, Hernán MA. Constructing inverse probability weights for marginal structural models. Am J Epidemiol 2008;168:656-64.

129 Brumback BA, Hernán MA, Haneuse SJPA, et al. Sensitivity analyses for unmeasured confounding assuming a margina structural model for repeated measures. Stat Med 2004;23:749-67.

130 Banack HR, Kaufman JS. Estimating the time-varying joint effects of obesity and smoking on all-cause mortality using marginal structural models. Am J Epidemiol 2016;183:122-9.
131 Howe CJ, Cole SR, Mehta SH, et al. Estimating the effects of multiple time-varying exposures using joint marginal structural models: alcohol consumption, injection drug use, and HIV acquisition. Epidemiology 2012;23:574-82.

132 Centers for Disease Control and Prevention. Opioid overdose. U.S. prescribing rate maps. Available: https://www.cdc.gov/ drugoverdose/maps/rxrate-maps.html [Accessed 17 Oct 2020].

133 Bachhuber MA, Arnsten JH, Starrels JL, et al. Willingness to participate in longitudinal research among people with chronic pain who take medical cannabis: a cross-sectional survey. Cannabis Cannabinoid Res 2018;3:45-53.

134 Vandenbroucke JP, von Elm E, Altman DG, et al. Strengthening the reporting of observational studies in epidemiology (STROBE): explanation and elaboration. Int J Surg 2014;12:1500-24. 